Commun. Fac. Sci. Univ. Ank. Series $\mathbf{A}_{2}, \mathrm{~A}_{3}$

V. 37, pp 59-78 (1988)

\title{
COMPOSITION ANALYSIS OF THE EQUILIPRATED SOLID- LIQUID PHASES IN THE BINARY EUTECTIC SYSTEMS WITH MICROPROB MICROANALYSER
}

\section{MEHMET GÜNDÜZ}

Eerciyes Üniversity, Faculty of Arts and Sriences Pysics Dept., Kayseri

\section{ABSTRACT}

Compositions of the equiliprated solid-lizquid phases in the Al-CuA! ${ }_{2}, \mathrm{Al}-\mathrm{Si}$ and $\mathrm{Pb}-\mathrm{Sn}$ systems were examined by using Cameea microprobe microanalyser. All the solid and liquid phases were found to be uniform for the systems. The measured consentraticns of the solid and liquid phases in the $\mathrm{Al}-\mathrm{CuAl}_{2}$ system, the solid phases in the $\mathrm{Al}-\mathrm{Si}$ system, the solid $\mathrm{Pb}$ and the liquid PbSn phases in the Pb-Sn system were in agreement with the phases diagram values. However the measured compositions of the solid $\mathrm{Sn}$ phase and liquid Al-Si phases were found to be quite different from the phase diagram values. The difference for the solid Sn phase came from the semaring effect, and the liquid AlSi phase might came from the very different obsorbsition coefficient for AIKa and SIK $a$ lines. The corrected consantration of the liquid AlSi phaso was aiso in good agreement with the phase diagram values.

\section{INTRODUCTION}

When a binary system is held in a constant temperature gradient for a long time (5-7 days) above the eutectic temperature, $\mathrm{T}_{\mathrm{e}}$, with a casting composition of, $\mathrm{C}_{0}$, (where $\mathrm{C} \alpha<\mathrm{C}_{0}<\mathrm{C}_{\mathrm{e}}$ or $\mathrm{C}_{\mathrm{e}}<\mathrm{C}_{0}<\mathrm{C}_{\beta}$, Fig.1), initially the alloy is a mixture of solid and liquid up to the liquidus temperature, (fig.1). The liquid droplets move up the temperature gradient direction according to TGZM, [Pfann, (1956), Allen and Hunt, (1979), Gündüz, (1987)]. The TGZM process is completed when the uniform liquid phase has a sharp solid-liquid interface with the uniform solid phase. The shape of the solid-liquid interface and the phases can be preserved by a rapid guenching. The thickness of the phases is mainly dependent on the casting composition, $\mathrm{C}_{0}$, and the equilibrium time, $t$, (the time to obtain the uniform solid and liquid phases) is mainly dependent on the applied temperature gradient of

ISSN 0378-6269; A. U. Basımevi

ISSN $0251-0863$ 


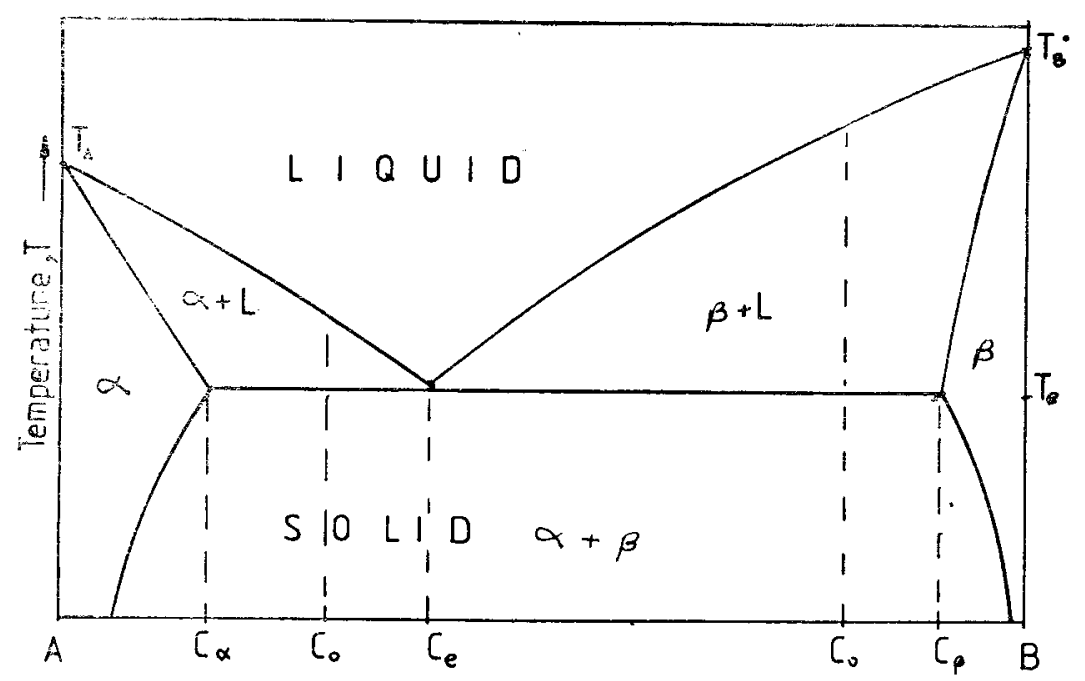

Fig.1. A binary equilibrium (eutectic) phase diagram.

the sample, [Gündüz, (1987)]. The composition of the equilibrated solid and liquid phases can be examined by a microprobe microanalyser.

Composition of the equilibrated phases in the $\mathrm{Al}-\mathrm{CuAl}_{2}, \mathrm{Al}-\mathrm{Si}$ and l'b-Sn systems were analysed by the microprobe microanalysis method. Before starting to discuss how the actual composition were obtained from the measured values, it is necessary to briefly examine the measurement of composition by microprobe analysis.

Compositions, $\mathrm{C}_{\mathrm{A}}$, for quantitative analysis are generally obtained in the form of an intensity ratio, $\left(k=I_{a}^{A} / I_{A}^{A}\right)$ equal to the peak count rate above the background, for a selected characteristic line from the sample, divided by that from a $100 \%$ standard examined under identical experimental conditions. To obtain accurate values of concentration, the intensity measurements must be corrected for dead time and background radiation, (fig.2). This corrected ratio is called the $k$ ratio and is given by

$$
\mathrm{k}=\frac{\mathrm{I}_{\mathrm{A}}^{\mathrm{a}}}{\mathbf{I}_{A}^{\mathrm{A}}}
$$

where $I_{A}^{a}$ denotes the corrected intensity of $A$ radiation from the specimen and $I_{A}^{A}$ the corrected intensity of $A$ radiation from the pure standart of $A$. 


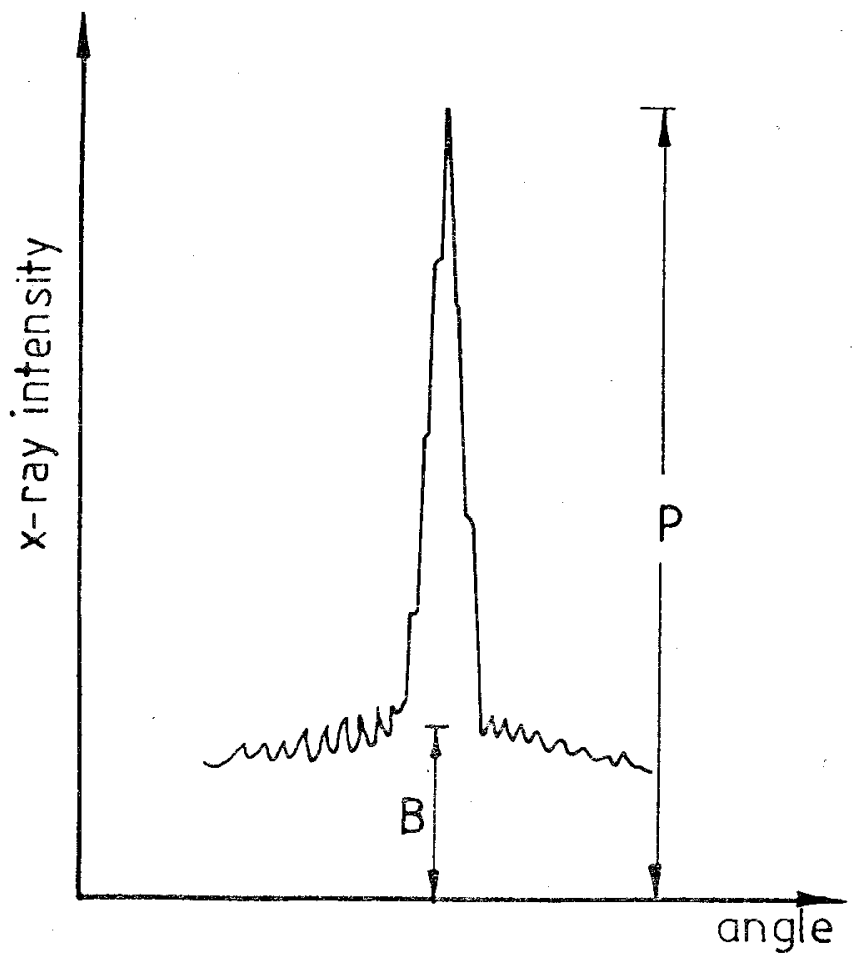

Fig.2. Definition of X-ray peak intensity $P$, and background intensity, $B$.

Having obtained high quality $k$ values, the problem then is to convert them into values for chemical composition without a loss of accuracy. In order to do this a correction procedure has been developed which is commonly known as 'ZAF' correction. This name arises from the fact that to obtain true concentrations from k-ratio data, it is necessary to apply in general atomic number $(Z)$, absorption (A) and fluorescence (F) corrections. The atomic number, Z, corrections [Cox, 1983] arises from the fact that the X-ray intensity of a characteristic line generated within a target depends not only on the concentration of the element, but also on the atomic numbers of all the constituent elements.

The absorption correction, [Love, 1983], A, arises from the fact that the X-rays generated are observed by the target material and that in general the attenuation in the specimen and standard are different. 
Photoelectric absorption, [Reed, 1983], F, is the mechanism by which $\mathrm{X}$-rays are attenuated and the correction which must be included is predominantly caused by the difference in mass absorption coefficents of specimen and standard. The 'ZAF' corrections are based on a considerable amount of theoretical and empirical work. Martin and Poole, (1971), Poole and Martin, (1969), Reed, (1975), Scott and Love, (1983), have presented detailed discussions of various correction procedures.

Tterative composition calculations, resulting from the ' $Z A F$ ' corrections and k-ratios are usualy taken as starting approximations to the true values. These compositions are conveniently carried out on a computer and a number of package-computer programmes are available to carry out data correction. The package-computer programmes which have been developed by Cameca based on the 'ZAF' correction technique are similar to those adopted by Colby, (1971).

\section{COMPOSITION ANALYSIS OF THE PHASES}

Composition profiles across the solid-liquid interface in the quenched liquid and in the single solid phase and parallel to the interface were measured, (Fig.3) using a fully automatic camebax microanalyser. $\mathrm{Al}, \mathrm{Cu}$ and $\mathrm{Si}$ elements were analysed using their $\mathrm{K} \alpha$ lines. $\mathrm{Pb}$ and $\mathrm{Sn}$ elements were analysed using their $L \alpha$ and $M \alpha$ lines respectively. An accelerating voltage of $20 \mathrm{kV}$ or $15 \mathrm{kV}$, a take off angle of $40^{\circ}, 20$ second counting times and two microsecond dead times were employed throughout. Pure element standards of $5 \mathrm{~N}$ 's purity were used. Counts were always collected from the specimens under exactly the same condition as from the standards. Care was also taken to ensure that there was no drift in beam current, voltage and spectrometer spositions over the period when analysis were being taken.

The composition profiles in the solid, away from the solid-liquid interface were examined by scanning the beam along a line vertical to the interface and approximately $200 \mu \mathrm{m}$ away from the grain boundary groove. Measurements of the composition were made at $2 \mu \mathrm{m}$ intervals in the 10 to $20 \mu \mathrm{m}$ distance from the interface and various intervals ranging from 10 to $25 \mu \mathrm{m}$ up to $1000 \mu \mathrm{m}$ in the solid phase.

Composition measurement using point analysis in the quenched liquid gives a too large scatter in the results. This is because the quenched 


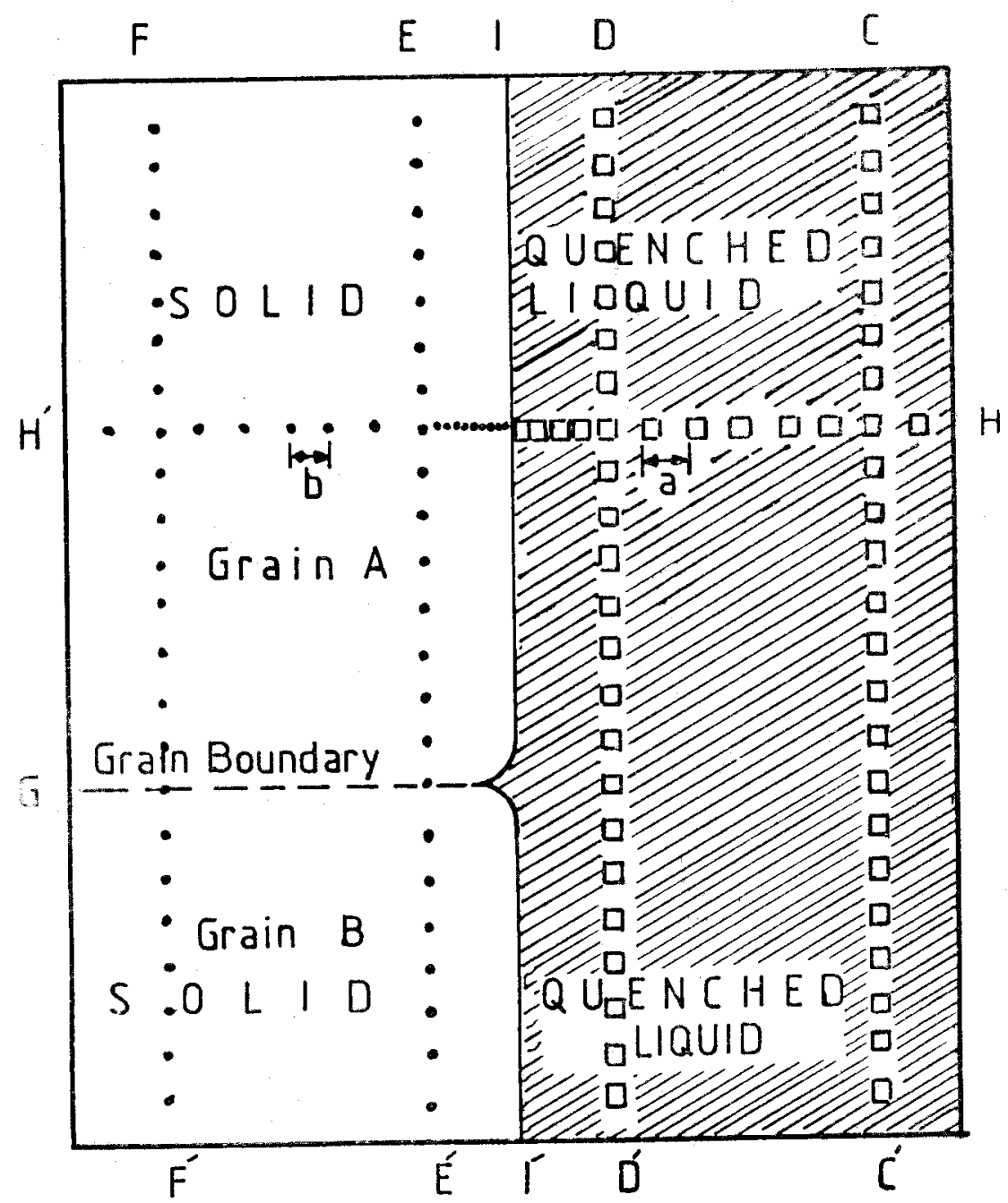

Fig.3. Schematic representation of the microprobe analysis for the phases $(\mathrm{HC}=150-200$ $\mu \mathrm{m}, \mathrm{ID}=\mathrm{IE}=40-50 \mu \mathrm{m}, \mathrm{IC}=\mathrm{IF}=400-700 \mu \mathrm{m}, \mathrm{CC}^{\prime}=2-5 \mathrm{~mm}, \mathrm{a}=15-30 \mu \mathrm{m}$, $\mathrm{b}=4-10 \mu \mathrm{m})$.

liquid is a mixture of phases, thus the composition profiles in the quenched liquid were measured using an area counting technique. The beam was scanned over a square of side $5 \mu \mathrm{m}$ and an area count was made at $5 \mu \mathrm{m}$ intervals in the range of up to $50 \mu \mathrm{m}$ from the interface and various intervals ranging from 10 to $25 \mu \mathrm{m}$ for up to $500-1000 \mu \mathrm{m}$. 
The composition profiles of the solid and liquid phases were also analysed parallel to the interface, 40 to $50 \mu \mathrm{m}$ and 400 to $700 \mu \mathrm{m}$ away from the interface (depending on the thickness of the phases).

\section{RESULTS AND DISCUSSIONS}

It must be noted that when the composition is measured near the interface ( $1 \mu \mathrm{m}$ to $2 \mu \mathrm{m}$ away from the interface) the detected ray is effected by the composition of the other phase, that is, when the composition is measured in the solid phase the detected ray is affected by the liquid phase and vice versa for the liquid phase.

The incident beam affects an area approximately a few $\mu \mathrm{m}$ wide and a few $\mu \mathrm{m}$ deep (figs.4 and 5). So the measured composition of the phase in the order of a few $\mu \mathrm{m}$ from the interface is not the actual composition of the phase because of the contamination effect from the other phase. The actual composition near the interface (as close as 0.1

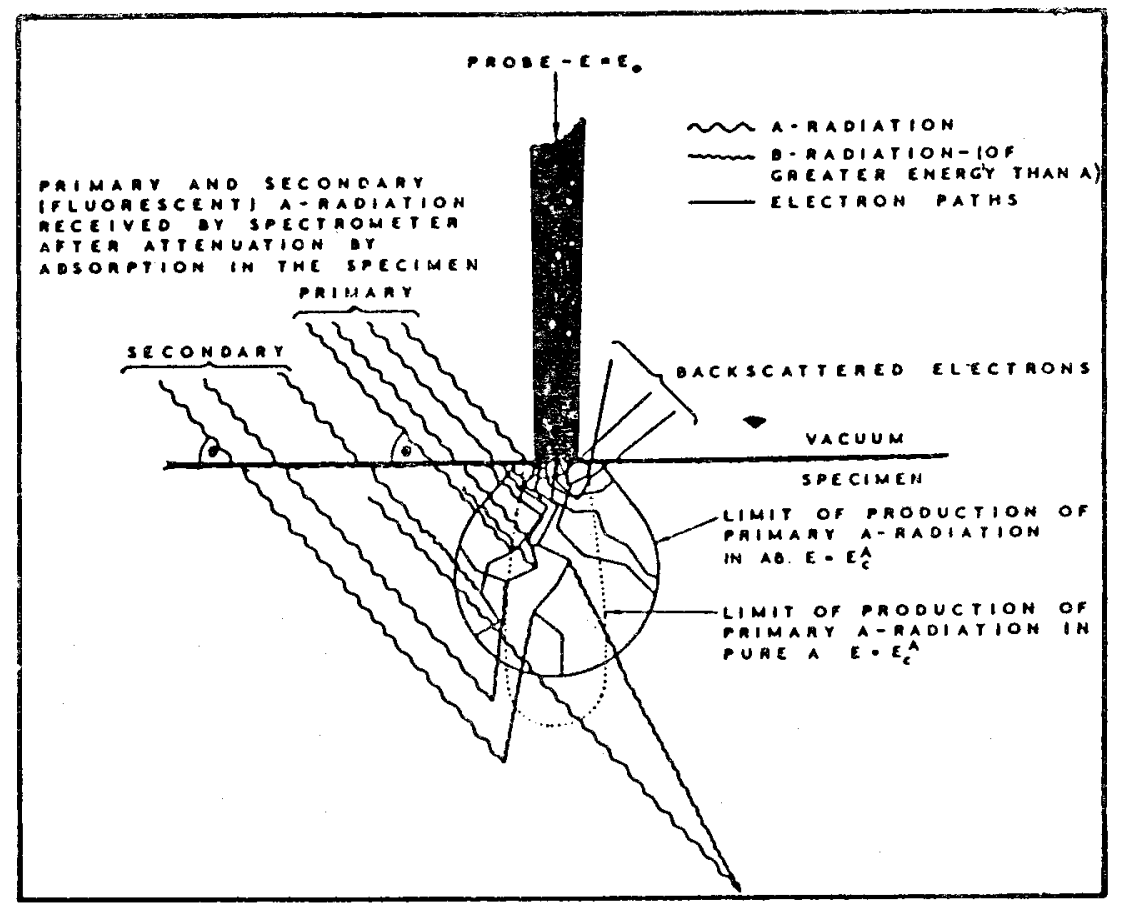

Fig.4. Schematic representation of the production of $\Lambda$ radiation in a specimen $A B$ for which $\mathrm{Z}_{\mathrm{A}}<\mathrm{Z}_{\mathrm{B}}$. (From Martin and Poole, 1971). 


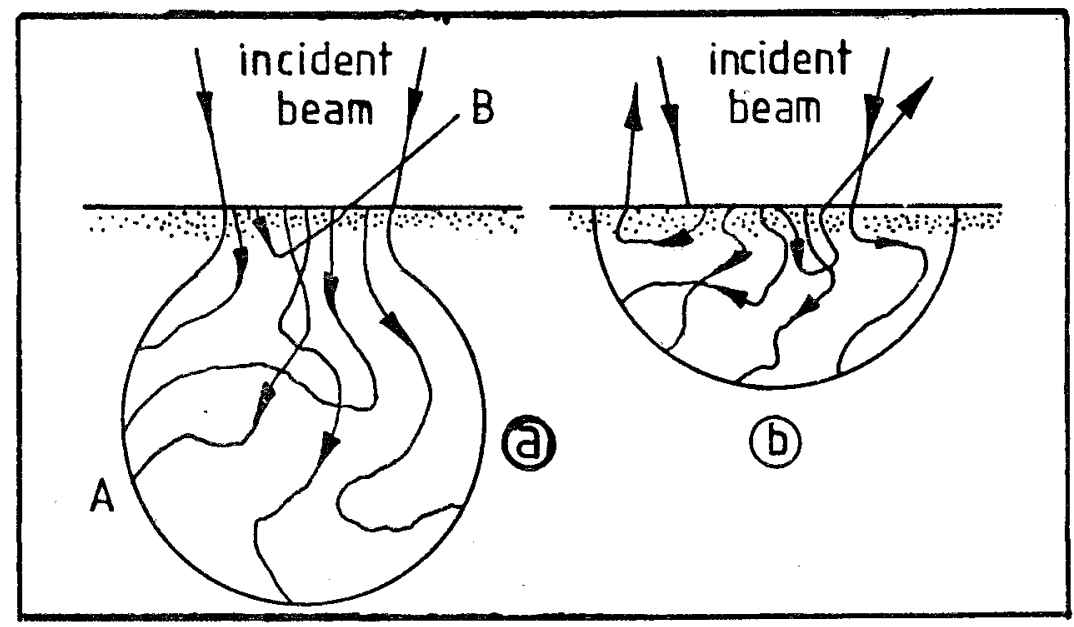

Fig.5. Electron scattering in:

a) a light element

b) a hevay element.

$\mu \mathrm{m}$ to the interface) may be the same as the rest of the phase. This can be seen clearly from Fig. $12 b$ which showss x-ray intensity composition current ray on the secondary electron image photograph (See also Figs. 11 to 14). The solid-liquid interface was found to be in the same position by comparing the secondary electron image photograph with the etched-sample optical microscope photograph for the same magnification. It appeared that there was no significant interface movement during the quench. There were no significant composition gradients in the phases. As can be seen from Fig. 6 to Fig. 8 the compositions are uniform within the error limits for both phases for $\mathrm{Al}-\mathrm{CuAl}_{2}, \mathrm{Al}$ $\mathrm{Si}$ and $\mathrm{Pb}-\mathrm{Sn}$ eutectic systems. However, in spite of the uniformity of the phases, the observed compositions, especially for the Al-Si quenched liquid is very different from the equilibrium phase diagram composition. The same effect was also observed by MeCartney (1981) and Fuchs and Tensi, (1984).

As can be seen from Figs. 6 to 8 composition profiles (using the 'ZAF' correction) are perfectly uniform for the solid phases (except the $\mathrm{Pb}$ phase) and reasonably uniform for the quenched liquid phase when measuring from a square of side $5 \mu \mathrm{m}$ and even more uniform composition profiles were obtained when using a larger square (a square of side $-16 \mu \mathrm{m}$, fig.7a). Inspite of the uniformity of the phases the measur- 


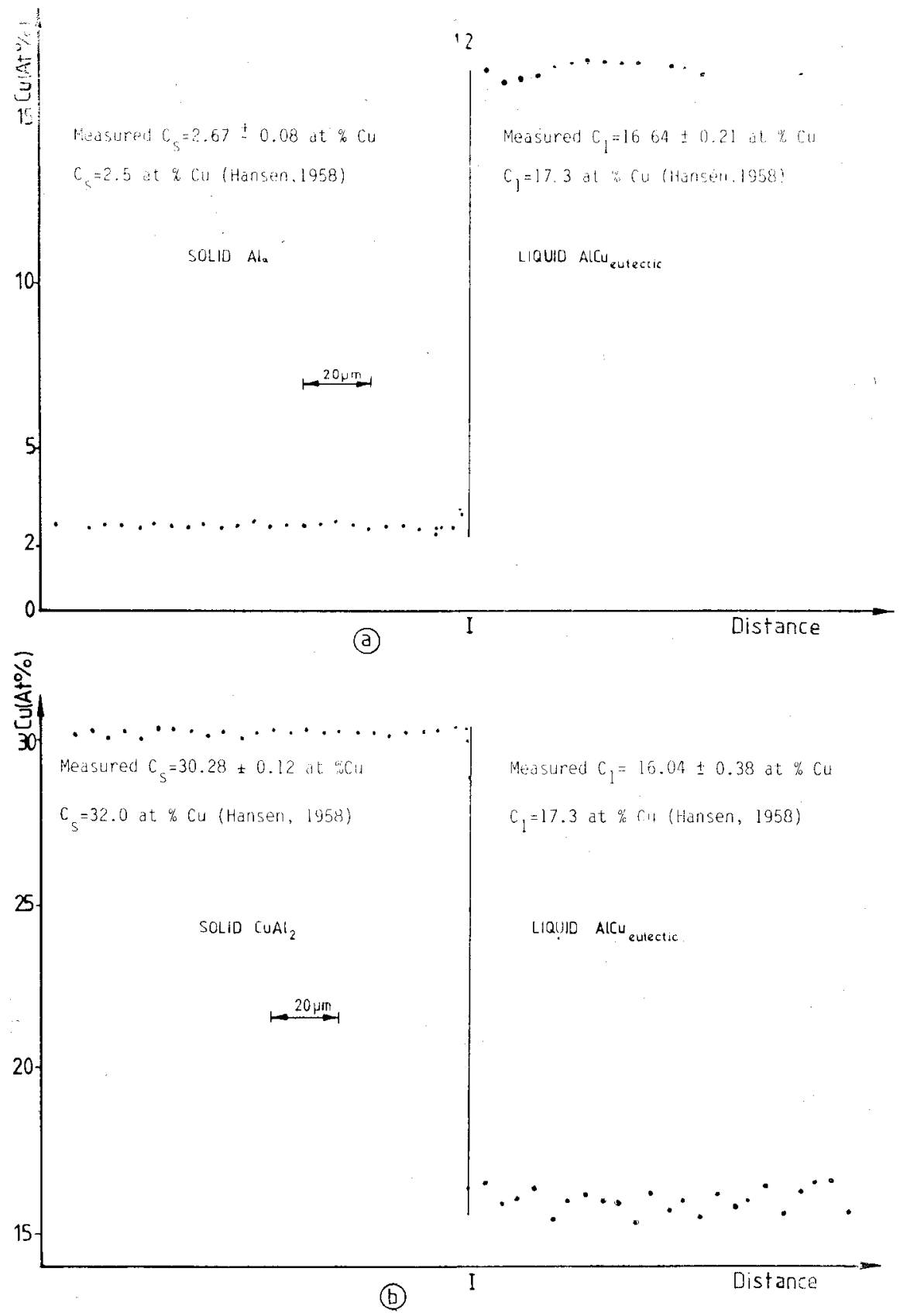

Fig.6. Composition profiles for Al-CuAl system. 


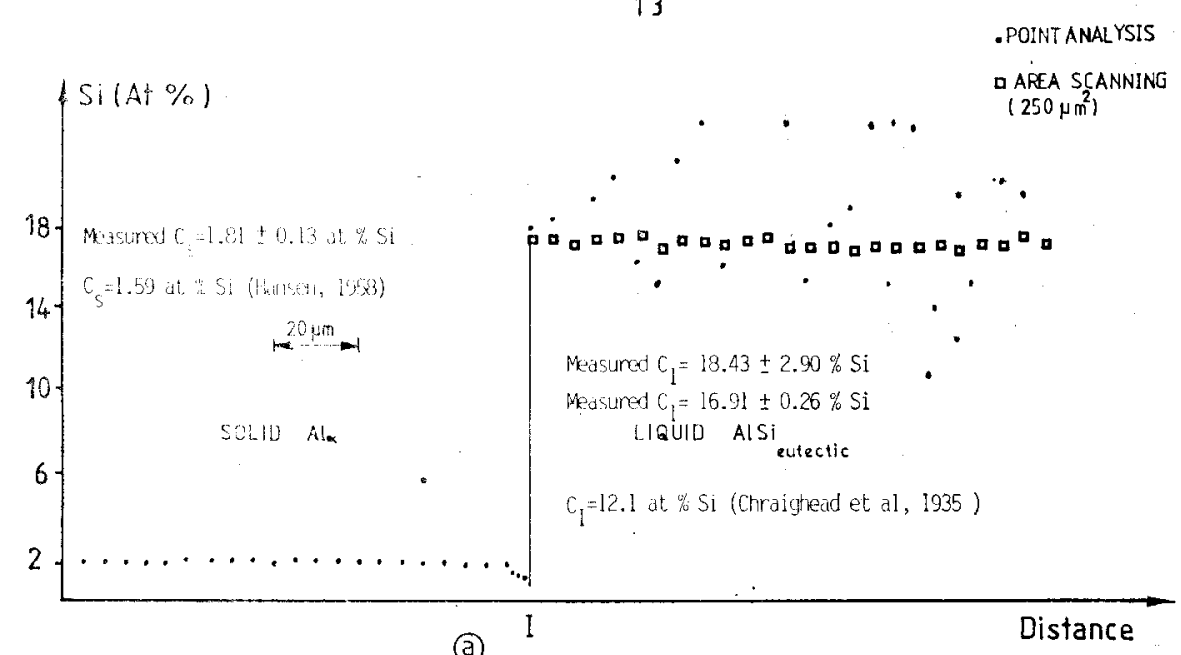

$$
\begin{aligned}
& \text { Test sample: } \mathrm{C}_{\mathrm{l}}=12.5 \text { at } \% \mathrm{Si} \\
& \text { Measured }: \mathrm{C}_{\mathrm{L}}=18.42 \pm 2.85 \text { at } \% \mathrm{Si}
\end{aligned}
$$

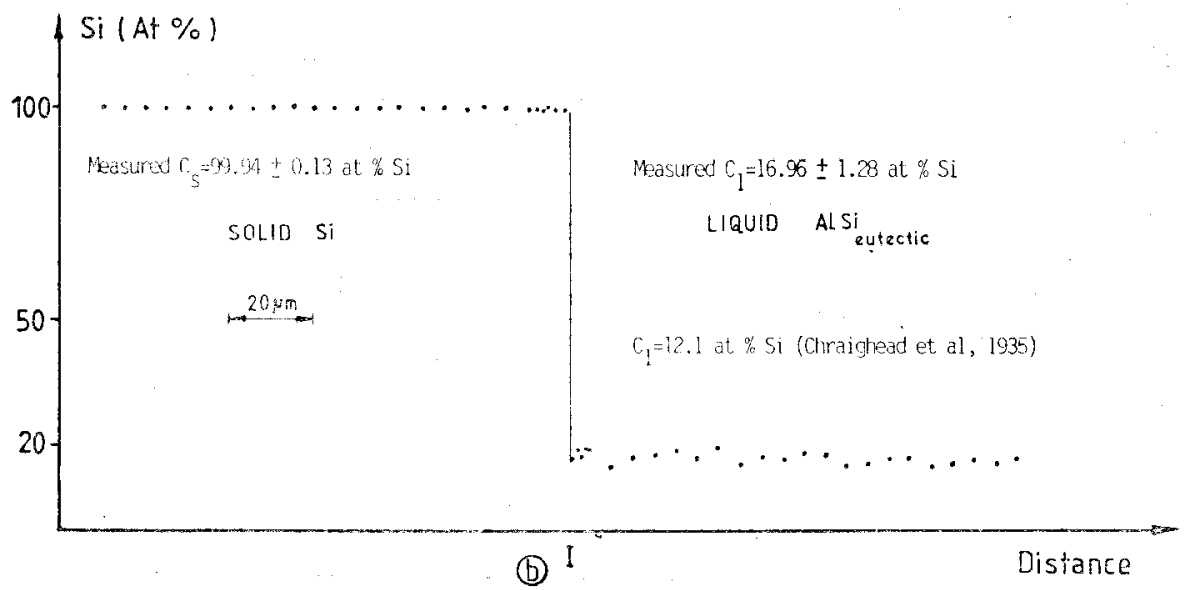

Fig.7. Composition profiles for Al - Si system.

ed composition using the 'ZAF' correction was slightly different for the quenched $\mathrm{Al}-\mathrm{CuAl}_{2}$ and $\mathrm{Pb}-\mathrm{Sn}$ phases and was higher for the AlSi quenched liquid phases than the equilibrium phase diagram compositions. The 'ZAF' procedure over-estimates the amount of absorb- 

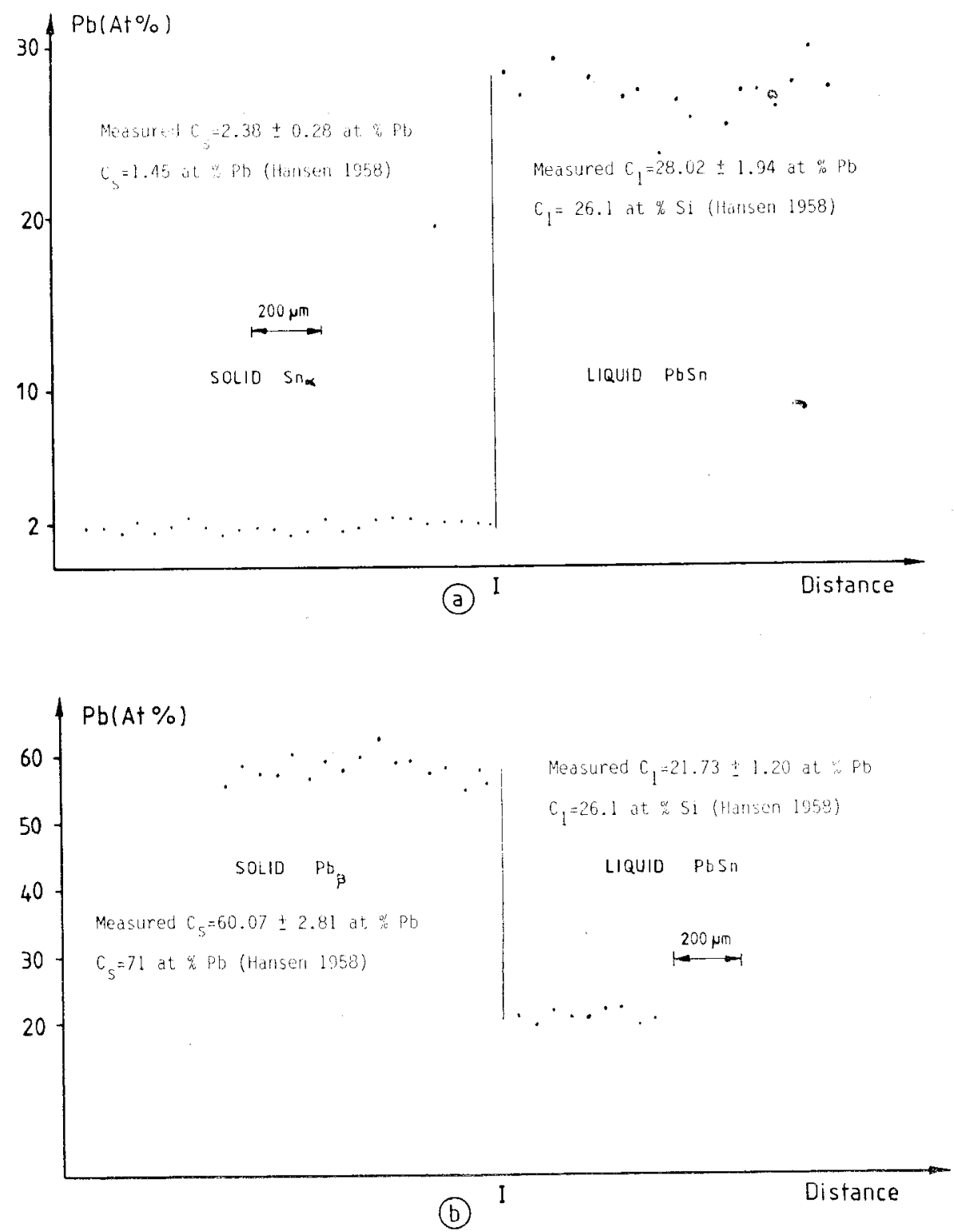

Fig.8. Composition profiles for Pb - Sn system.

tion of $\operatorname{SiK} \alpha$ radiation by silicon and aluminium. It is important to note that $K \propto$ radiation from $\mathrm{Si}$ is strongly absorbed by Al. The absorption coefficient of $\operatorname{SiK} \alpha$ is 503 while the absorption coeficient of 
the same line by pure $\mathrm{Al}$ is 3492 , (Reed, 1975) and hence gave 'ZAF' corrected composition which were too large. So, a relatively large absorption correction is required for the SiK $\alpha$ radiation. Thus the accuracy of the correction procedure for the AlSi quenched liquid was checked in the following way.

Molten alloy of known composition, $\mathrm{Al}-13 \mathrm{wt} \% \mathrm{Si}$, was kept in the vacuum melting furnace for about two hours, stirred, poured into a cylindrical graphite crucible and quenched. A test sample containing a transverse and longitudinal section from the middle part of the specimen was prepared for microprobe analysis. The microprobe analysis was carried out in the same way as for the equilibrated solid-liquid interface sample. The measured composition from the test sample was found to be in good agreement with the quenched liquid phase (from the equilibrated solid-liquid interface sample) composition.

Salter (1984) has numerically calculated 'ZAF' corrected and actual values of $\mathrm{Si}$ for the $\mathrm{Al}$ - Si system, (table. 1). So a calibration graph was obtained by plotting actual compositions versus measured ' $Z A F$ ' corrected compositions (fig. 9). This calibration graph was subsequently used to obtain the actual weight fractions of silicon from the 'ZAF' corrected values. The actual eight fraction of silicon for the equilibrated liquid phase $(12-13 \mathrm{wt} \% \mathrm{Si})$ and for the test sample (12-13 wt $\% \mathrm{Si}$ ) are found to be in good agreement with the phase diagram values (11.7 - 12.7 wt \% Si), (Chraighead et al, 1935).

Calibration graphs (the 'ZAF' corrected composition versus actual composition) may be obtained for $\mathrm{Al}-\mathrm{CuAI}_{2}$ and $\mathrm{Pb}-$ Sn systems in the same way in order to obtain more accurate quenched liquid compo-

Table 1. The correction required for AlSi quenched phase.

\begin{tabular}{|l|l|l|l|l|l|l|l|l|l|l|l|l|}
\hline Area \% Si & 0.0 & 0.1 & 0.2 & 0.3 & 0.4 & 0.5 & 0.6 & 0.7 & 0.8 & 0.9 & 1.0 \\
\hline $\begin{array}{l}\text { 'ZAF' } \\
\text { corrected } \\
\text { Wt \% Si }\end{array}$ & 0.0 & 0.146 & 0.279 & 0.401 & 0.513 & 0.617 & 0.712 & 0.799 & 0.877 & 0.944 & 1.0 \\
\hline $\begin{array}{l}\text { 'ZAF" } \\
\text { corrected } \\
\text { Wt \% Al }\end{array}$ & 1.0 & 0.904 & 0.806 & 0.707 & 0.607 & 0.506 & 0.405 & 0.303 & 0.201 & 0.099 & 0.0 \\
\hline $\begin{array}{l}\text { True } \\
\text { Wt \% Si }\end{array}$ & 0.0 & 0.088 & 0.117 & 0.270 & 0.365 & 0.463 & 0.564 & 0.668 & 0.775 & 0.886 & 1.0 \\
\hline $\begin{array}{l}\text { True } \\
\text { Wt \% Al }\end{array}$ & 1.0 & 0.912 & 0.823 & 0.730 & 0.635 & 0.537 & 0.436 & 0.332 & 0.225 & 0.114 & 0.0 \\
\hline
\end{tabular}




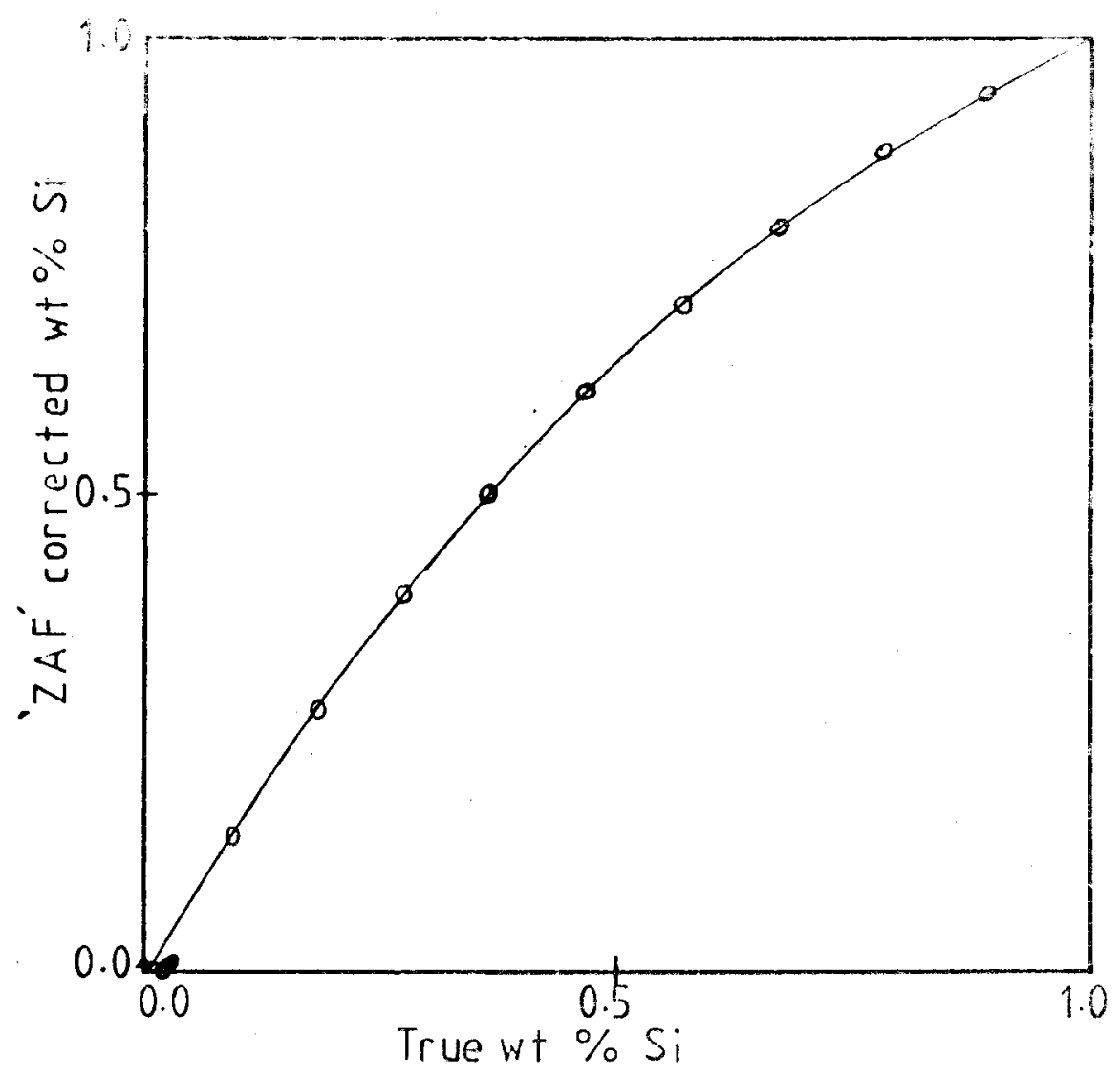

Fig.9. Correction required for AJ - Si composition measurement.

sitions. 'ZAF' corrected micro analysis results are in good agreement with the phase diagram values for $\mathrm{Al}-\mathrm{CuAl}_{2}$ and $\mathrm{Pb}-$ Sn eutectic systems (except the Sn phase). As can be seen from fig. 10 without slightly etching it is impossible to obtain a concentration profile for the $\mathrm{Pb}-\mathrm{Sn}$ system, because of a smearing effect. Slightly higher concentration measurements (than the phase diagram values) and scattered values might be due to the smearing effect, precipitation of the Sn particle to the $\mathrm{Pb}$ phase and the etching effect. Etching gives surface contamination and roughening both of which can influence the elements detected and the number of back scattering electrons. An error in the order of $5 \%$ might be excepted from microprobe analysis. Recently Bennett and Kirkwood (1984) used the microprobe analysis 


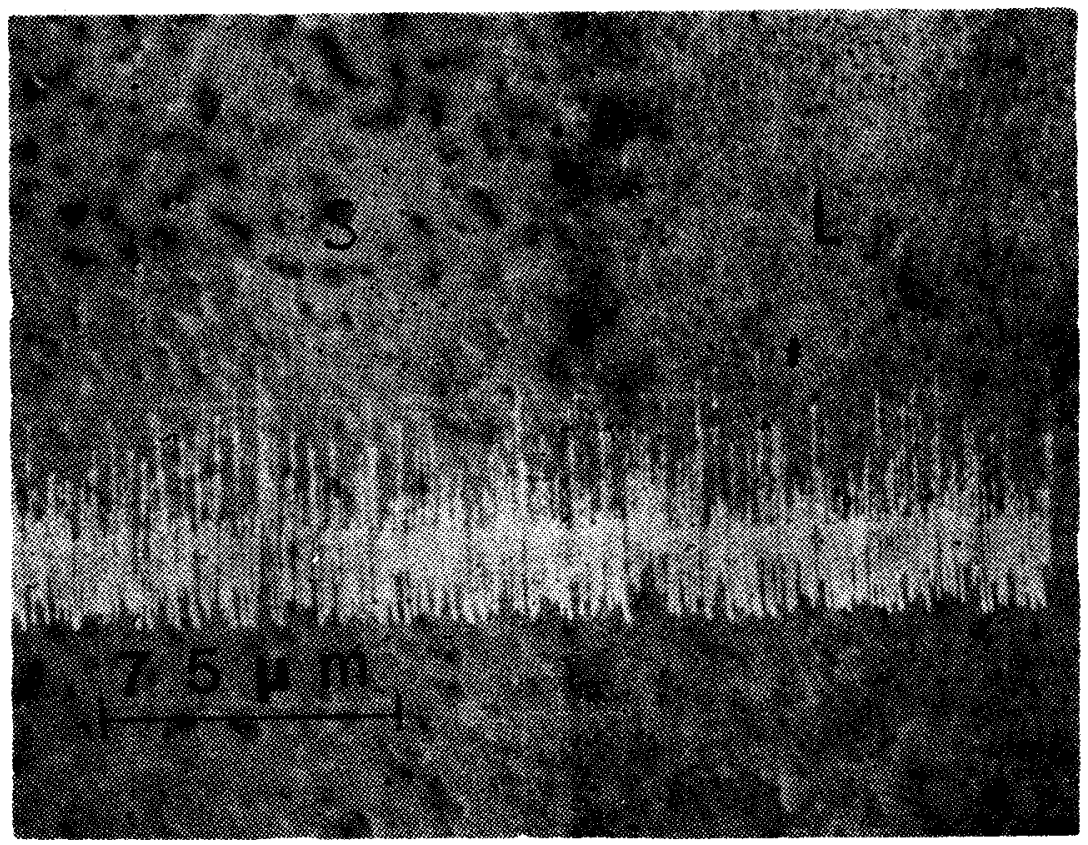

Fig.10. Smearing effect, (Solid Pb - liquid PbSn system).

technique to measure the liquid phase composition in $\mathrm{Al}-\mathrm{Cu}$ and Al - Cu - Fe systems. They estimated that the accuracy of their measurements was $\pm 4 \%$ for copper and $\pm 10 \%$ for iron.

A line scan provides information which is intermediate between that given by a scanning image and a point analysis. Therefore, the line scan simply shows the composition profile of the phases (for small magnification $(<\mathrm{X} 800)$ there is incident $X$-ray beam tilt effect) and the relative composition difference between the phases (see Figs.11 to 14).

As can be seen from Figs. 6 to 8 the measured compositions of the $\mathrm{Al}$ - $\mathrm{CuAl}_{2}$ system (solid $\mathrm{Al}$, solid $\mathrm{CuAl}_{2}$ and $\mathrm{CuAl}$ quenched liquid), $\mathrm{Al}$ - Si system (solid Al, solid Si and AlSi quenched liquid) and $\mathrm{Pb}$ Sn system (solid, $\mathrm{Pb}$ solid $\mathrm{Sn}$ and $\mathrm{PbSn}$ quenched liquid) are in good agreement with the equilibrium phase diagram values, (table. 2). The composition of both the solid and liquid phases as shown in figs. 6 to 8 and figs. 11 to 14 are uniform. 


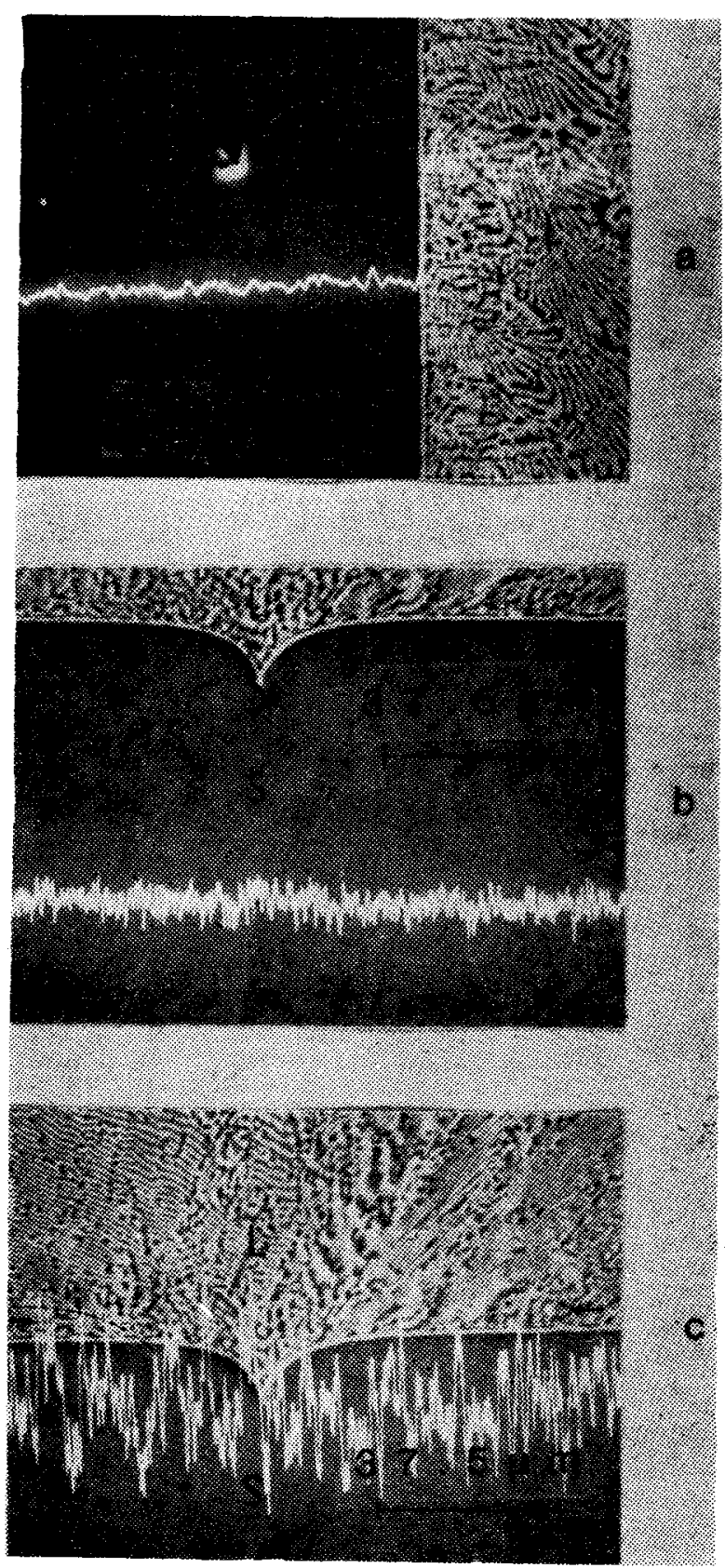

Fig.11. Cumposition profiles for the solid Al - liquid AlCu system with the line analysis. 

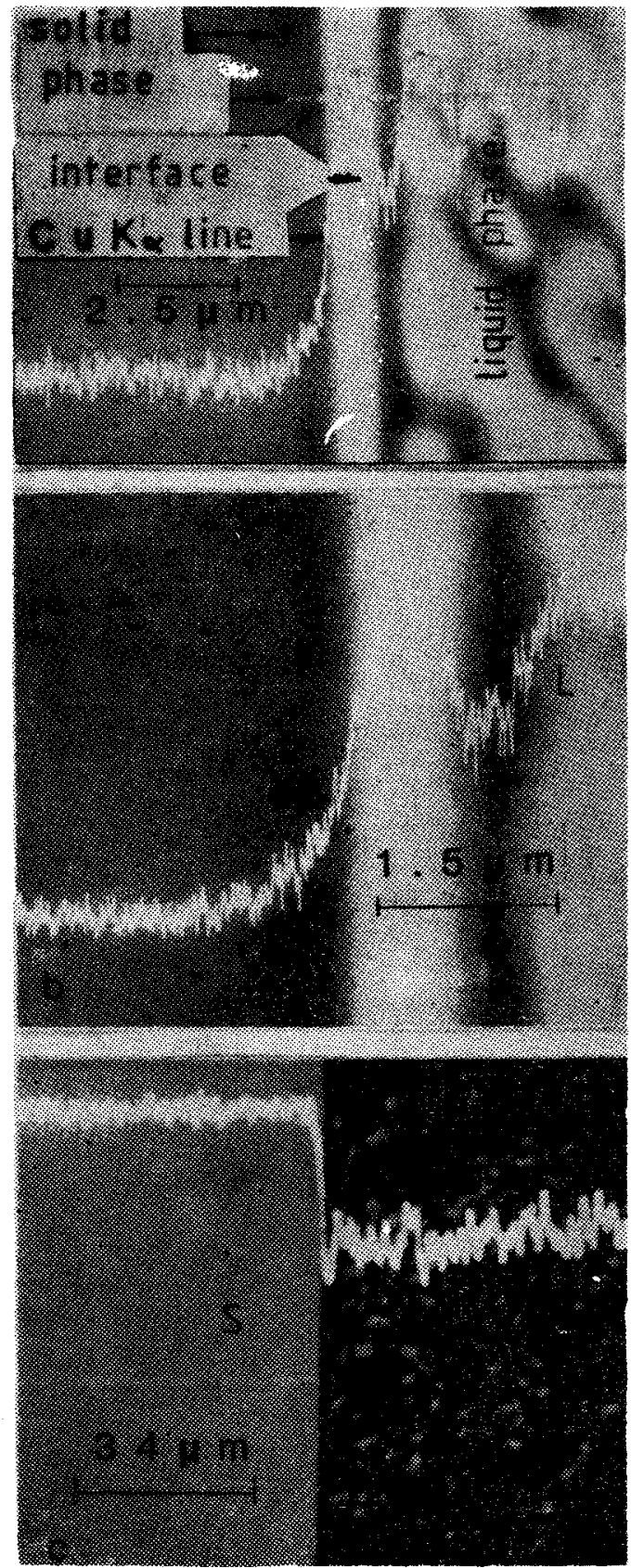

Fig.12. Composition profiles for $\mathrm{Al}-\mathrm{CuAl}_{2}$ system with the line analysis. a,b) Solid Al - liquid AICu system.

c) Solid $\mathrm{CuAl}_{2}$ - liquid AlCu system. 

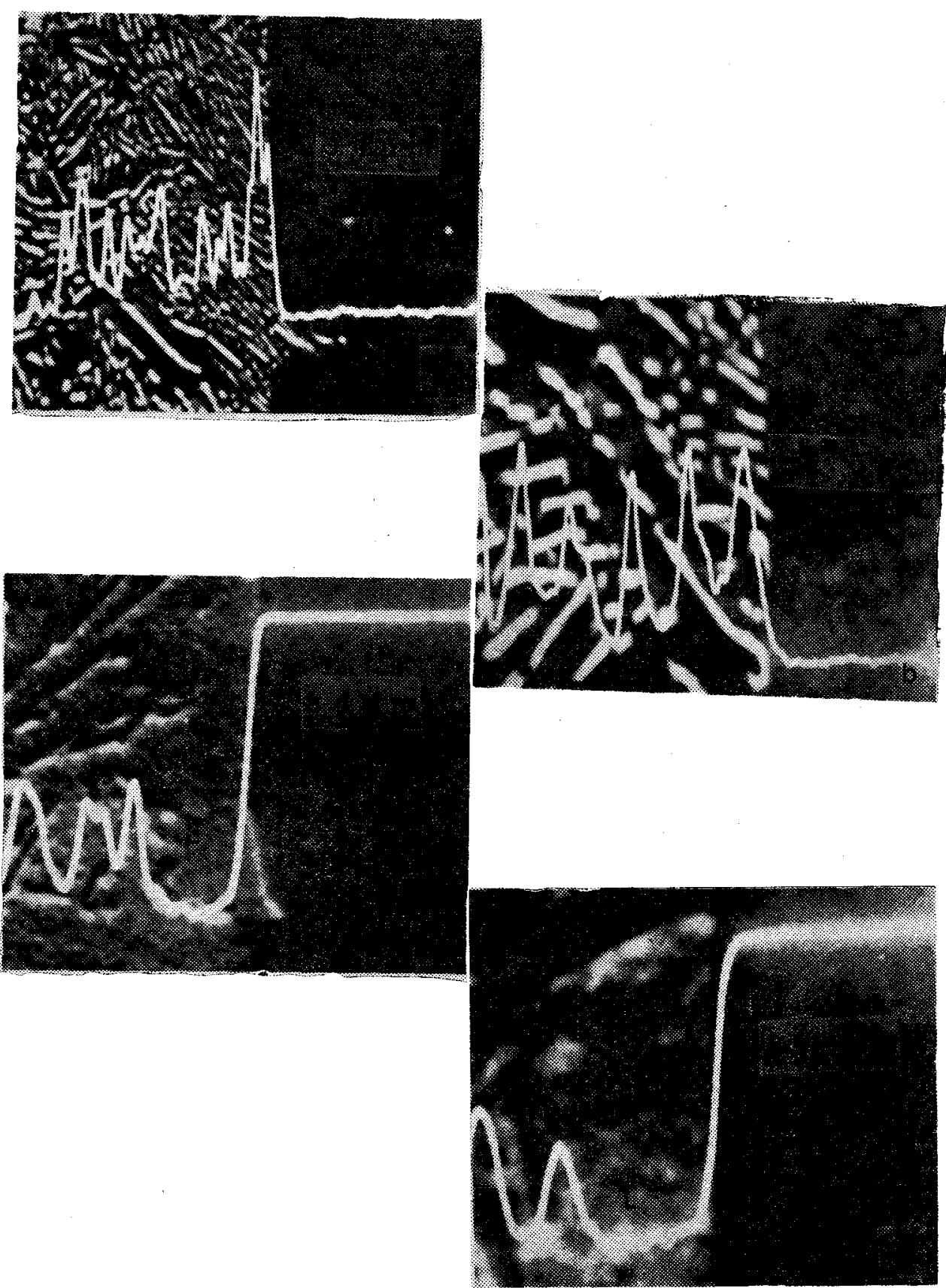

Fig.13. Composition profiles for Al-Si system with the line analysis. a,b) Solid Al-liquid ALSi system, c,d) Solid Si-liquid AISi system. 

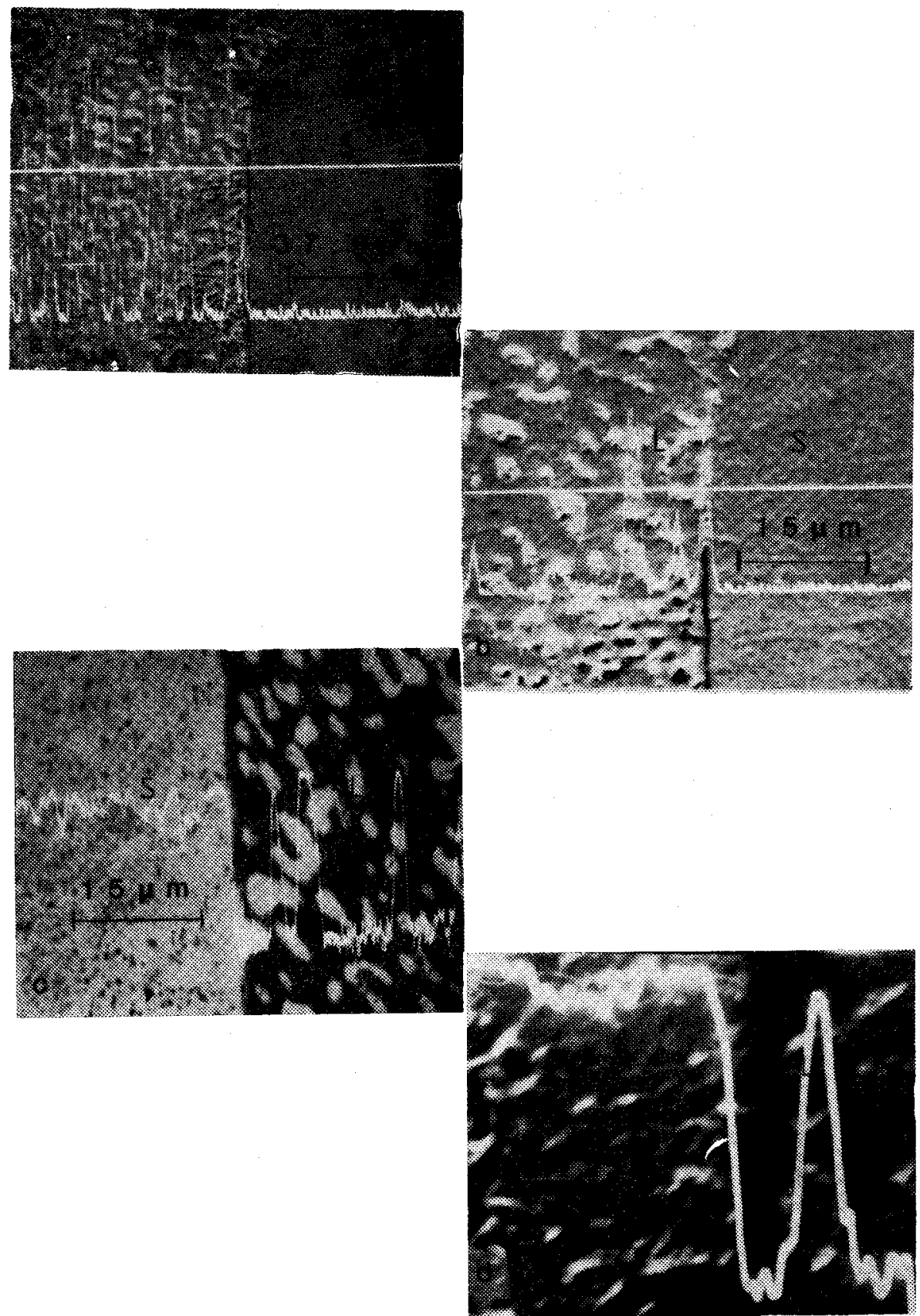

Fig.14. Composition profiles for $\mathrm{Pb}-\mathrm{Sn}$ system with the line analysis. a,b) Solid Sn-liquid PbSn system, c,d) Solid liquid Pb-Sn system. 


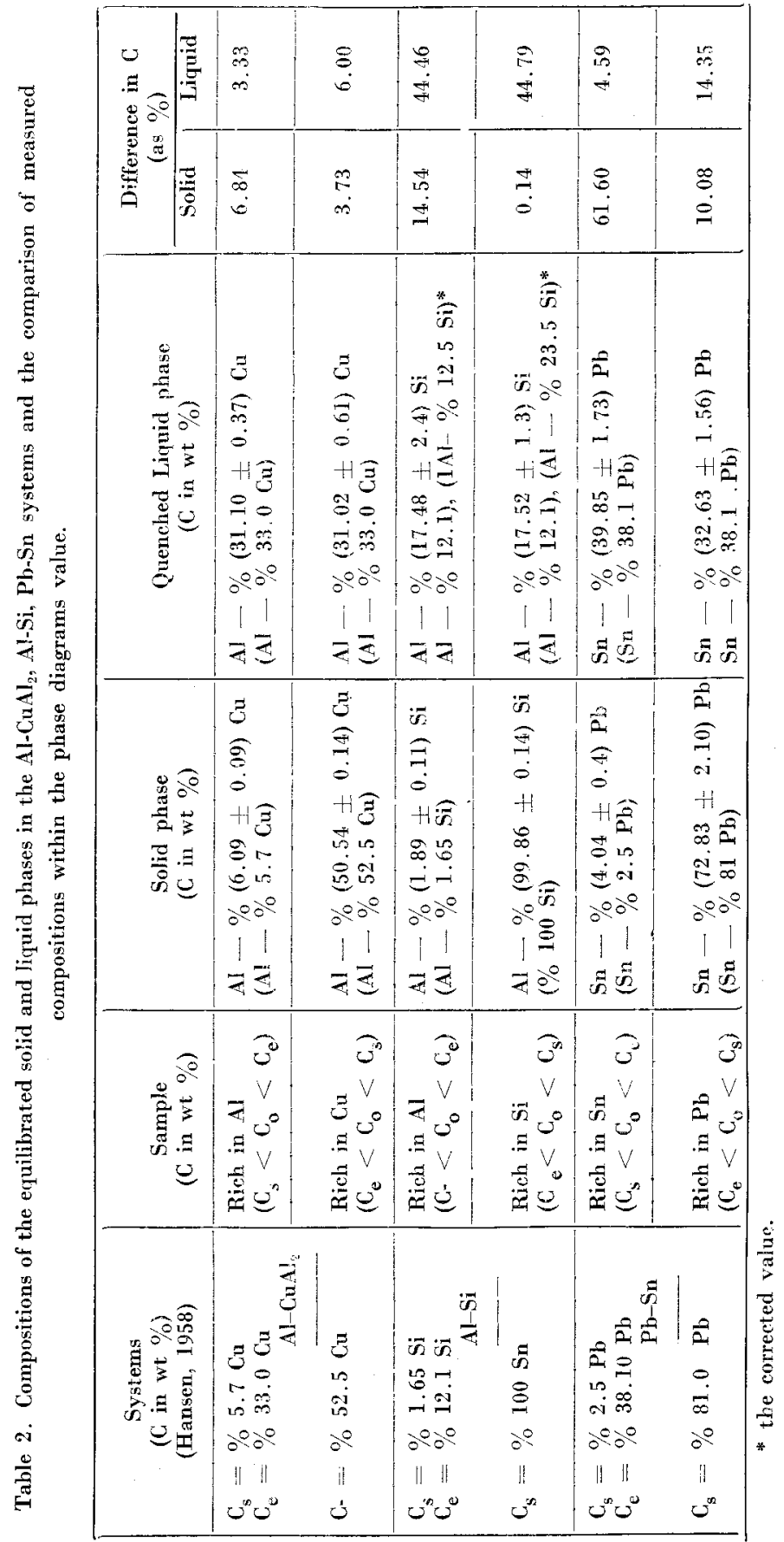




\section{CONCLUSTON}

a) At the equilibrium, the solid and liquid phases are separated with a sharp interface.

b) Composition of the solid phase can be examined by point analysis method.

c) In order to obtain reliable composition for the liquid phases area scanning method must be used,

d) The line analysis gives the composition distribution and the relative ratios of the composition.

e) The analysis shows, that at the equilibrium all the phases are uniform and the measued compositions are in good agreement with the phase diagrams values.

\section{ACKNOWLEGEMENTS}

Experiments described in this work have been conducted in the Department of Metallurgy and Science of Materials, Oxford University. The auther would like to thank Professor Sir P.B. Hirsh, F.R.S. and J.W. Christian, F.R.S. for prodiving laboratory facilities.

\section{REFERENGES}

ALLEN, D.J. AND HUNT, J.D.: Solidification and Casting of Metals PP.39, Metal society, 1979, London.

BENNET, D.A. AND KIRKWOOD, D.H.: Met.Sci., 18, (1984), 17.

BLOCH, R.: Mikrochim Acta Suppl., I. (1966), 232.

CHRAIGHEAD, C.H.: CAWTHORN, E.W. AND JAFFEE, R.I.: Trans. AIme. 203 (1935), 81. COLBY, J.: Proc. of VI. Nat. Conf. of EPASE, Pitssburg, PA, (1971).

COX, M.G.C.: Quantitative Electron-Probe Microanalysis, pp. 147, Ellis Horwood Ltd, (1983.) New York, (Ed.Scott, Y.D. and Love, G.).

FUCHS, H. AND TENST, H.M.: Praktische Metallographit, (1984).

GÜNDÜZ, M.: Türk Fiziği Derneği 9. Ulusal Fizik Kongresi 16-18 Eylül 1987 Uludağ Ün. BURSA

HANSEN, M.: Constitution of Binary Alloys, MCGraw-Hill, (1958).

LOVE, G.: Quantitative Electron-Probe Microanalysis, pp.163, Ellis Horwosd Ltd, (1983), New York. 
MARTIN, P.M. AND POOLE, D.M.: Met. Rev., (Rev. no. 150), (1971), 19.

MeCARTNEY, D.G.: D.Phil. Thesis, Oxford $\ddot{U}_{n .}$ (198I).

PFANN, W.G.: Trans. AIME, 20, (1956), 961.

POOIE, D.M. AND MARTIN, D.M.: Met. Rev., (Rev.no.133), 14, (1969), 61.

REED, S.J.: Quantitative Electron-Probe Microanalysis, pp. 193, Ellis Horwood Ltd, (1983), New York.

REED, S.J.: Electron Microprobe Aualysis, Cup, (1975).

SALTER, S.C.: Private communication (1984).

SCOTT, V.D. ANI) LOVE, G.: Quantitative Electron-Probe Microanalysis. Ellis Horwood Ltd, (1983), New York. 